\title{
Educação e Inclusão nas cidades e as \\ pessoas com deficiência
}

\author{
Rasteiro, Domingos \\ Instituto Piaget, Almada, Portugal \\ drasteiro@sapo.pt
}

\author{
Oria Segura, Maria Rosa \\ Universidade de Extremadura, Badajoz, Espanha \\ mro@uex.es \\ Ruivo, João \\ Instituto Politécnico, Castelo Branco, Portugal \\ ruivo@ipcb.pt
}

\section{Resumen}

En diferentes documentos internacionales se reconocen variadas formas de exclusión que sufren las personas con discapacidad en las ciudades en las que viven: bajo nivel de participación cívica, bajos niveles de integración social, falta de acceso a los medios de información, bajos niveles de convivencia social, dificultades de acceso a los bienes comunes y a los servicios de apoyo, problemas de accesibilidad en los espacios públicos y los edificios, problemas de movilidad y de transporte, mayores dificultades de subsistencia económica y vivienda, entre otras limitaciones. La investigación que se presenta procura identificar las políticas y los proyectos socioeducativos que fomentan la inclusión social de las personas necesidades especiales en las ciudades. El estudio se centró en las ciudades portuguesas que forman parte de la Red Internacional de las Ciudades Educadoras, cuya "Carta de Principios» apunta a una intervención de las autoridades locales, en el sentido de combatir la exclusión social, promoviendo a través de la educación formal, no formal e informal los proyectos centrados en las comunidades y que contribuyan a la participación de los ciudadanos, las instituciones sociales y las educativas para que las ciudades sean más inclusivas.

A través de un conjunto de instrumentos de recogida de datos y de un trabajo de naturaleza cualitativa se hace una observación de las diferentes ciudades, utilizando las técnicas de recogida documental, de entrevista a informantes privilegiados, especialmente políticos, técnico y dirigentes municipales de las organizaciones representativas de las personas con discapacidad e a personas con discapacidad y las instituciones educativas y sociales que llevan a cabo los proyectos inclusivos.

A través de la metodología comparativa el objetivo final es caracterizar los fundamentos, las buenas prácticas socioeducativas y las realidades que hacen a las ciudades de estudio más inclusivas que fomenten la equidad de acceso a los recursos y las oportunidades educativas, culturales y sociales a los ciudadanos con necesidades especiales.

\section{Abstract}

It's acknowledged in several international documents the many forms of exclusion that people with special needs suffer in the cities they live in: low level of civic participation, low levels of social integration, lack of access to information sources, low levels of social interaction, limited access to common goods and to helping services, mobility and transportation problems, increased economic and habitation problems, amongst other problems. The investigation work that presents looks to identify the politics and social educative projects that promote social inclusion of people with special needs in the cities. The study focused on the Portuguese cities that are a part of the International Association of Educating Cities, which the Letter of Principles aims for an interventions of the local authorities, in a way of fighting social exclusion, promoting, trough formal, non-formal and informal education, projects centered on the communities and that contribute, through the participation of the citizens, social institutions and educational institutions, to a more inclusive city.

Through a set of data gathering instruments and field work of qualifying nature it will be made an observation of different realities, using the techniques of document collection, interview to privileged informants, such as, politicians, technicians and municipal directors as well as the representative organizations of people with special needs and the social and educational institutional that carry through the projects.

Through comparative methodology, the final goal is to characterize the foundations, the social and educational practices, and the realities that make the studied cities more inclusive.

Palabras clave:. Inclusión Social / Ciudades Educadoras e Inclusivas / Educación Comparada / Necesidades Especiales / Políticas Locales.

Keywords: Social inclusion/ Educating and inclusive cities/ Comparative Education/ Special needs and local politic. 
A educação tem vindo a ganhar uma grande centralidade no desenvolvimento das sociedades contemporâneas, pois os desígnios da educação estão hoje para além da formação dos indivíduos e ganhou outras dimensões do espaço e do tempo. Se a educação familiar tinha uma grande importância, por via da socialização primária do individuo, ganhou maior relevância com a universalização da escola, que institucionalizou a educação como uma forma de adquirir conhecimentos mais especializados e essenciais para as sociedades progredirem. Com o desenvolvimento das democracias e as novas formas de organização social e politica que isso implica, a educação alcançou foros de cidadania, pois a vida em sociedades abertas implica uma aprendizagem do exercício da cidadania e da participação cívica na vida das comunidades e dos países. Se para além da democracia representativa tivermos em conta a dimensão da democracia participativa, que implica novos modelos de governança, a educação é decisiva para a organização da vida coletiva dos povos. A educação tem alastrado a sua influência dos micro, dos mesos para os macro sistemas sociais, estando presente em todos os lugares: as famílias, as escolas, as comunidades, as empresas, as cidades, os países e até o mundo que pelos mecanismos da globalização exige, cada vez mais, competências para compreender a sua complexidade e exige uma visão multifatorial de conjunto dos diferentes fenómenos sociais, culturais, económicos, ambientais e políticos.

Mathew (2018), (ex-diretor do programa ONU- Habitat e ex-alcaide de Barcelona), refere a importância da educação para a cidadania e a formação cívica como suportes fundamentais aos processos de governança nas cidades, sendo que as cidades pela sua densidade, pelos níveis do seu crescimento, pela amplitude dos seus recursos, pelos fluxos de comunicação que gera, pelos centros de desenvolvimento económico, social e cultural em que se foram transformando, são hoje espaços e contextos produto da evolução, do empenho coletivo das sociedades humanas, pelo que fará todo o sentido considerar a educação como um valor e uma estratégia determinante para garantir a democracia, o progresso e a inclusão social.

\section{A EDUCAÇÃO NA CIDADE INCLUSIVA}

Pela primeira vez no relatório da Unesco Aprender a Ser, de Faure (1972), fala-se da cidade educativa, especificamente, o capítulo IV intitulado «Instituição Escolar e Cidade Educativa», no sentido em que os especialistas, envolvidos na redação do relatório, referiam a necessidade de aproximar a escola da vida. Nesse contexto, a educação extra-escolar ${ }^{1}$ era uma forma de ter acesso a um amplo conjunto de recursos a que a escola e os professores deveriam deitar mão para preparar as pessoas para a vida em sociedade.

Este relatório redigido entre 1971 e 1972, data da sua publicação, dá enfase a duas ideias fortes para as políticas educativas futuras: a da educação permanente e das cidades educativas, não deixando de exprimir preocupações com o crescimento económico, a modernização dos países e a formação de mão-de-obra mais competente, com vista a uma produção de maior qualidade.

Como chama a atenção Lima (2004), neste texto da Unesco, a educação assume um conceito mais político e passível de ser objeto de uma ação política, responsabilizando os poderes públicos pela sua orientação.

O bem comum, a solidariedade e a cooperação assumem, explicita e implicitamente, um grande protagonismo nas recomendações apresentadas pela comissão, as quais insistem no facto de aprender a ser significar aprender a viver e de a educação representar a chave de uma democracia participativa (p.10).

A educação é vista, nesta perspetiva, como uma política social de generalização da igualdade de oportunidades, reforçando o papel dos Estados nas suas diferentes componentes, governos centrais, locais e regionais, encarando a educação como sendo um direito social e humano básico. É neste

\footnotetext{
${ }^{1}$ A educação extra-escolares aqui definidas na perspetiva de Morissete e Gingras (1993), como forma de consolidar e acrescentar aquelas experiências que são próprias do currículo formal.
} 
quadro que surge o movimento das cidades educadoras, que procura ser uma referência para os municípios que estão empenhados neste processo permanente de olharem para o sistema educativo ${ }^{2}$, partindo de uma leitura das necessidades locais e das expectativas das suas comunidades. Como é referido por Fernandes (s.d.):

Ao chamar-se a atenção para o papel educativo da cidade, há uma instituição que é convocada para assumir um papel de liderança na coordenação e dinamização de uma política educativa com base neste espaço urbano: essa instituição é o município. (p.2).

Segundo o mesmo autor, os municípios dispõem de instrumentos e recursos que favorecem uma visão integrada e global do valor da educação no contexto da comunidade e do meio, para além da legitimidade própria que lhe assiste na definição das políticas de educação. Se numa perspetiva do Estado, o Município teria um papel complementar ou instrumental, na educação pública nacional, a nível da cidade educadora, o município tem o papel de promotor, de dinamizador das potencialidades educativas locais que, pela rede de recursos, possa melhorar a qualidade de vida da cidade e do território.

A proximidade com os problemas e com as potencialidades que os municípios têm desenvolvido as suas políticas numa certa tensão, entre o que lhes é exigido pelo exercício das suas competências específicas, que derivam da lei, e o sentido de responsabilidade que advém do exercício da cidadania que coloca problemas novos e necessidades prementes a que urge dar resposta. Assim, têm despontado muitas das políticas de bem-estar, da educação, da saúde e dos serviços sociais que, estando para além da dimensão universal das respostas, procuram soluções heterogéneas a situações que emergem do quotidiano da vida das comunidades. Foi desse modo que muitos municípios portugueses, nas últimas quatro décadas, foram o veículo de acesso a uma vasta gama de recursos formativos, como sejam: a música, as artes, o conhecimento da história e do património local, o fomento dos projetos educativos, o apoio às associações de pais e o reforço do seu papel na vida das escolas, contrabalançando as competências legais com as competências reais. Sobre esta matéria pode-se atentar no que diz Del Pozo (2003):

Si lo que se pretende es promover un compromiso fuerte de la administración con el gran reto social de la educación, no podemos limitarnos -los Ayuntamientos- a perspectivas gestionarlas o administradoras del hecho educativo, sino que hemos de incorporarnos activamente al debate político y legislativo sobre cuestiones pedagógicas y sociales (p.3).

O que está em causa é que a responsabilidade pela educação deve ser um desígnio de toda a sociedade, de todas as comunidades, havendo necessidade de regular melhor os poderes públicos, no sentido de diminuir a centralização e a homogeneização, abrindo um domínio, tão sensível para o futuro coletivo, ao compromisso de todos. Cada vez fica mais evidente a dificuldade de agir de forma centralizada para abordar questões de proximidade tão intimamente ligadas às vivências comunitárias e sociais das comunidades humanas. Voltando a referir Subirats (2003), quando diz:

El mundo local (...) en su conjunto mantiene la escala humana necesaria para vehicular sentimientos de pertenencia, esenciales en la vida de las personas y que aunque parezca paradójico, aumentan a medida que la globalización y la mundialización van tomando más fuerza (p.223).

Como é referido por Caballo y Villar (2001) existe, um binómio educação e território que é muito visível na integração dos projetos sociais, culturais e institucionais que estão presentes nas escolas e nas comunidades locais. Citando vários autores, Caride (1994), designa essa dimensão relacional do território como sendo: sociedade pedagógica para Beillerot, sociedade educativa para Husen, sociedade educadora para Agazzi ou cidade educativa para Faure.

A cidade, na sua função educadora, assume o meio como contexto favorável à formação, procura propostas integradoras e entende a educação como um domínio que ganha, num espaço territorial, uma dimensão integrada e permanente. Na verdade, o processo educativo depende muito de tudo aquilo que rodeia a pessoa humana e sabe-se que, nas aceções desenvolvimentistas, esse processo está muito dependente da interação do sujeito com esse meio envolvente. Daí que, quanto mais significa-

\footnotetext{
${ }^{2}$ O sistema educativo definido na Lei de Bases, Lei 44/86, de 14 de Outubro, conforme artigo $1^{\circ} \mathrm{n}^{\circ} 2$, é o conjunto de meios pelo qual se concretiza o direito à educação, que se exprime pela garantia de uma permanente ação formativa orientada para favorecer o desenvolvimento global da personalidade, o progresso social e a democratização da sociedade.
} 
tivo for o meio, quantos mais estímulos e experiências ele proporcionar, melhor serão os processos educativos que nele ocorre. Como refere um especialista da obra de Jean Piaget, Philips Jr. (1977), o cérebro humano não é um recetáculo passivo, mas é um sistema dinâmico que constrói os próprios mecanismos de captação do meio ambiente, sendo capaz de adquirir o conhecimento através das experiências físicas e da transmissão social, pelo que o meio é uma forma de encorajar à experimentação e ao pensamento.

O meio urbano é um espaço muito denso de informação, gerador de conhecimento de cultura e muito rico de relações humanas, podendo, por isso, desempenhar uma função socializadora, através de inúmeras estratégias de formação e de educação que são, por vezes, denominadas por currículo oculto mas que são processos essenciais de cidadania. A propósito das cidades e da educação, Trilla Brenet (1999), apresenta três dimensões essenciais: a cidade como ambiente educativo, a cidade como agente e recurso educativo e a cidade como conteúdo educativo.

Sobre a cidade, como lugar de educação, poder-se-ão enumerar múltiplos exemplos: as estruturas educativas formais, os espaços de educação permanente, a animação sociocultural, os múltiplos equipamentos com funções educativas, as bibliotecas, os museus, os centros cívicos, os teatros, os centros de exposições, os eventos com interesse formativo, os espetáculos, as relações sociais e de vizinhança que ocorrem nas cidades. É no pressuposto de que as cidades e os territórios têm uma potencialidade educativa, que emerge o conceito de "cidade educadora», como forma de olhar de modo inovador para a força da educação como motor da socialização, da coesão social, das novas práticas de aprendizagem e da mobilização de novos atores (municípios, associações, entidades empresariais e todo o tecido social), numa abordagem que está para além da visão tradicional de que esse é um processo reservado à família, à escola e ao Estado

O conceito de cidade educadora que nos é apresentado por Trilla Brenet(1999), implica que aos tradicionais ambientes educativos, a família e a escola se acrescente a cidade, como espaço de trocas e de aprendizagem. Neste sentido, a cidade assume-se como um agente e um recurso educativo a juntar a tantos outros que hoje desempenham essa função, um meio tanto mais rico quanto mais oportunidades, quanto mais recursos disponibilizar, quer em termos de quantidade quer em termos de qualidade e finalmente, pelos conteúdos educativos que pode gerar, muito vocacionados para as temáticas da atualidade da vida nas cidades e muito importantes como conteúdos para o desenvolvimento da cidadania e da democracia: a história, os valores, o ambiente, a solidariedade, a participação entre muitos outros que se podem desenvolver.

Estas ideias transformaram-se num movimento, que teve lugar em 1990, na cidade de Barcelona, onde decorreu o I Congresso Internacional das Cidades Educadoras com o tema de «Cidades Educadoras na Infância e na Juventude» onde estiveram presentes 70 cidades, representadas pelos seus Governos Locais, que assumiram a responsabilidade de melhorar a vida dos seus concidadãos, assumindo que a educação deveria ser considerada como um aspeto primordial do bem-estar da comunidade e que deveria privilegiar a cidade como um espaço para a sua concretização. Na Assembleia Geral da Associação, em 1999, na cidade de Jerusalém, foi aprovada a necessidade de que a cidade educadora transcendesse as primeiras idades e a escola, para passar a dizer respeito a toda a população e a todos os campos, como sejam: o urbanismo, o planeamento, a cultura, os serviços sociais, o meio ambiente, o desporto, a economia, a saúde, entre outras áreas. Em 1994, aquando da realização do III Congresso, na cidade de Bolonha, este movimento tomou a forma de Associação Internacional das Cidades Educadoras (AICE).

Outra data, que se constitui como marco deste movimento, foi a realização do Congresso de Génova, em 2004, (VIII Congresso) onde se procurou responder às mudanças que ocorreram, entretanto, nas sociedades e nas cidades, de forma a incorporar novos aspetos, como sejam: a interculturalidade, a formação ao longo da vida, as pessoas com dependências, as tecnologias da informação, o desenvolvimento sustentável, etc. Conforme concretiza Del Pozo (2013), a reforma da Carta em Génova, visou desenvolver algumas ideias que permitem ampliar e aprofundar o conceito, procurando agregar os seus 20 artigos à volta de três princípios:» o direito à cidade educadora», com seis artigos; "o compromisso de cidade», com seis artigos; e, "ao serviço integral das pessoas», com oito artigos

Atualmente (janeiro 2018) estão associadas 493 cidades de 37 países de todo o mundo: da Europa, 398 cidades de 14 países; da Ásia Pacífico, 28 cidades de 6 países; da América, 57 cidades de 12 países; e de África, 9 cidades de 5 países. Em Portugal a AICE tem 69 cidades associadas, que constituem a rede portuguesa das cidades educadoras. 


\section{UMA INVESTIGAÇÃO ATRAVÉS DA METODOLOGIA COMPARADA}

Estudar este problema foi o principal objetivo do trabalho de investigação que se levou a cabo e que se caracterizou por pretender realizar um estudo descritivo, de natureza qualitativa, enquadrado por uma metodologia comparativista e que enforma o que a literatura convencionou por designar por estudo de caso.

Nesta perspetiva, a abordagem da metodologia utilizada em educação comparada é muito útil, pois a mesma permite compreender os sistemas educacionais, ou de aspetos com eles relacionados, por meio da comparação dos casos e das unidades de estudo. Como refere Garcia Garrido (1991), não existe uma ciência comparativa na educação, mas uma metodologia comparada aplicada à educação. Este método serve para estudar vários problemas educativos, sobretudo, quando isso implica estudar dois ou mais fenómenos do mesmo tipo, procurando deduzir as discrepâncias ou as semelhanças entre si, interpretando os fundamentos ou as razões dessas diferenças. É neste contexto que se utilizou no presente estudo o contributo da educação comparada, procurando, através da comparação das políticas das cidades fazer emergir um enquadramento compreensivo do seu valor educativo e social na problemática das cidades inclusivas para as pessoas com deficiência.

Como refere Ball (1994) esta foi uma maneira de «estar por dentro» dos processos que conduziram e orientaram uma determinada política educativa. Muitos desses processos não são do conhecimento público e só se conseguem recolher através de depoimentos e fontes primárias, sendo, por isso, necessário proceder a uma triangulação dos dados para validar os discursos e os factos. O universo do estudo foram as cidades portuguesas que fazem parte da rede internacional das cidades educadoras este critério prende-se com o facto de essas cidades terem subscrito a Carta das Cidades Educadoras. O trabalho desenvolveu-se em 2016 e centrou-se na recolha de informação sobre:

a. quais os meios e oportunidades de formação, entretenimento e desenvolvimento pessoal que as cidades oferecem aos grupos com necessidades especiais;

b. como fomentam as cidades, em termos de planeamento, de ordenamento do espaço físico, respostas que favoreçam o acesso dos cidadãos com necessidades especiais aos espaços de convívio, de lazer, de equipamentos e serviços comunitários;

c. como são desenvolvidas as políticas locais de fomento da coesão social, por forma a incluir socialmente todos, em particular os cidadãos com necessidades especiais.

Utilizaram-se instrumentos e técnicas em uso, neste quadro metodológico, como sejam: a análise documenta lo inquérito por questionário, as entrevistas, procurando levantar as perceções que os decisores políticos e demais atores locais, incluindo pessoas com deficiência tinham acerca das condições de inclusão da sua cidade. Utilizou-se o questionário como recurso para a recolha de informação a um grupo alargado de informantes, 57 cidades que, à data, pertenciam à Associação Internacional das Cidades Educadoras (AICE).

Com a aplicação do referido questionário (validado qualitativamente por comité de especialistas e pré teste), a que responderam 31 cidades, foi possível selecionar as duas cidades e os dois municípios com maior potencial inclusivo. Os critérios para essa seleção tiveram, sobretudo, relação com os recursos e os serviços disponíveis na cidade e o acesso aos mesmos (por exemplo: transportes, acessibilidades, acesso à informação, recursos educativos e formativos tempos livres, cultura, desporto, saúde, emprego e habitação...) Nas cidades realizaram-se entrevistas aos informantes privilegiados dos municípios (Vereadores, Técnicos Municipais, cidadãos com deficiência e dirigentes de associações locais ligados à problemática) para se obterem informações mais detalhadas e mais aprofundadas que permitam identificar as políticas, as medidas e as ações de inclusão social numa dada unidade de estudo. 
Gráfico 1- Escala ordenada das cidades conforme o potencial de inclusão.

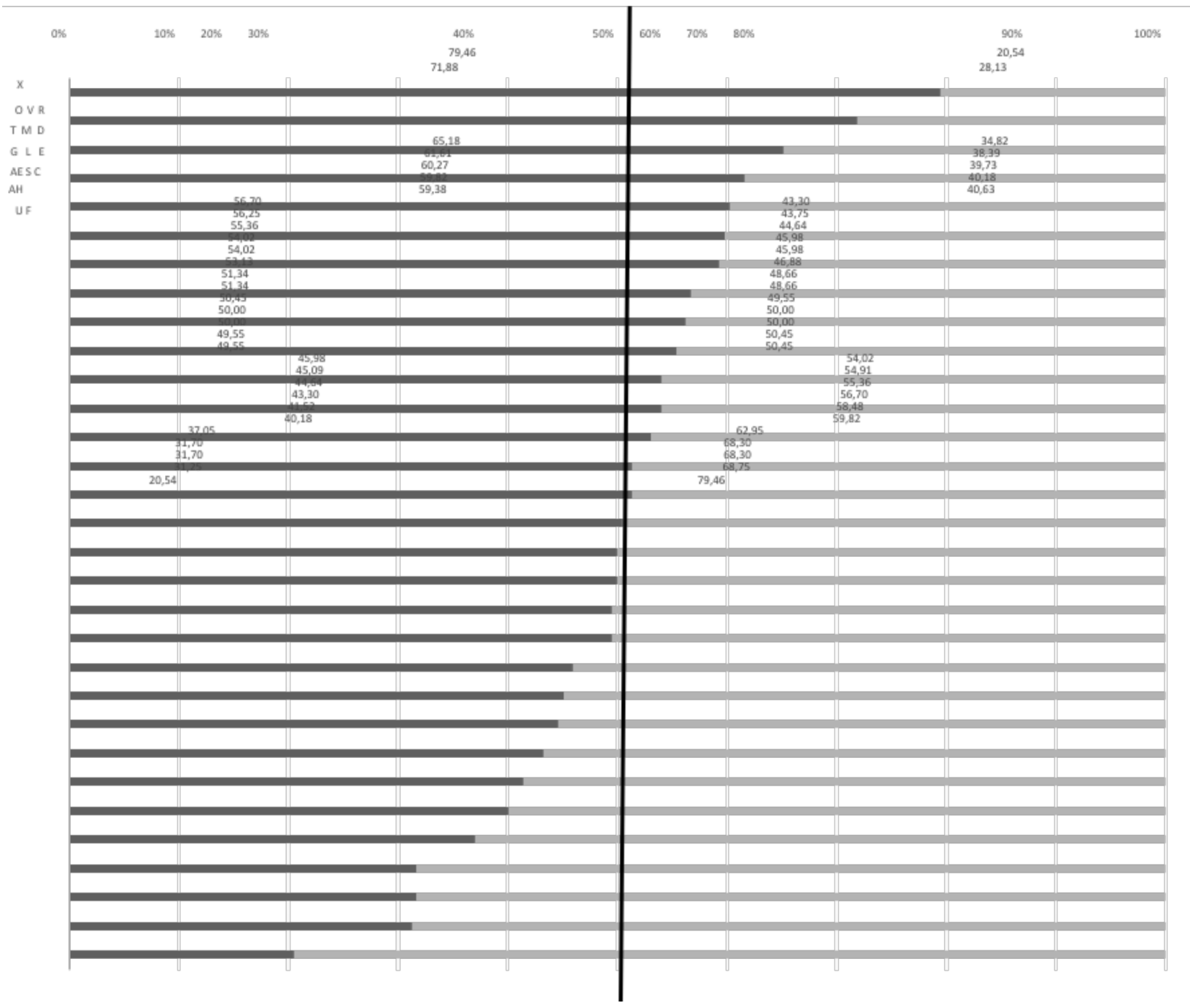

Através da análise e tratamento dos resultados do inquérito por questionário foi possível construir uma escala ordenada conforme a perceção que os respondentes expressam acerca do potencial inclusivo no tendo em conta as pessoas com deficiência e à resposta às suas necessidades (Gráfico 1). Aplicaram-se os parâmetros de análise já referidos no ponto 4 relativo à metodologia, organizando-se uma arrumação da cidade que obteve maior percentagem de pontos $(79,4 \%)$ para a que obteve menos pontuação $(20,5 \%)$, A percentagem alcançada por cada cidade foi encontrada entre a pontuação obtida (barra escura) e a diferença para a pontuação máxima (barra clara), ou seja, a cidade que obteve maior percentagem ainda ficou a $20,6 \%$ da pontuação desejável e a que obteve menos pontuação ficou aquém do desejável $79,4 \%$. São sete as cidades que estão num intervalo entre os $80 \%$ e os $60 \%$, treze as cidades estão no intervalo entre os $50 \%$ e os $60 \%$, seis cidades estão na casa dos $40 \%$, quatro na casa dos $30 \%$ e uma na casa dos $20 \%$.

Pelos scores que se obtiveram no questionário, pode dividir-se os processos de inclusão em três tipos padrão. As cidades que estão ainda num estádio embrionário, que estão agora a despertar para 0 problema mas não têm trabalho relevante no terreno, as cidades que estão num estádio de arranque das ações e das medidas inclusivas, mas que ainda necessitam percorrer todo um caminho de concretização mais consistente e, finalmente, as cidades que estão num estádio de desenvolvimento, já arrancaram, têm trabalho no terreno, está assumido no seu projeto politico e de desenvolvimento, têm dispositivos e meios que já as distinguem dos estádios anteriores e conseguiram montar um processo de envolvimento ao nível local, das instituições, das entidades, das escolas, das associações de e para as pessoas com necessidades especiais e entendem o trabalho feito como um processo em desenvolvimento que carece de continuidade e de mais meios para progredir. 
Quadro 1- Análise das áreas fortes e fracas.

\begin{tabular}{|c|c|c|c|}
\hline Áreas Fortes & Áreas Emergentes & Áreas Fracas & Áreas muito fracas \\
\hline Educação e formação & Serviços sociais & Acessibilidades edifícios & $\begin{array}{c}\text { Plano estratégico de promoção } \\
\text { da acessibilidade }\end{array}$ \\
\hline Convívio social & Serviços gerais & Barreiras arquitetónicas & Habitação \\
\hline & Serviços de saúde & Transportes & \\
\hline & Acesso à informação & Tempos livres, desporto, cultura & \\
\hline & Estudos e diagnóstico & Trabalho & \\
\hline
\end{tabular}

Seguindo a tendência geral dos resultados do estudo as categorias onde se tem feito mais progresso são os recursos disponíveis nas cidades para a educação e para a formação e as oportunidades para o convívio social com um valor de $69,8 \%$ e $70,8 \%$ respetivamente. Os serviços sociais existentes com $61,4 \%$, os serviços de saúde com $60,3 \%$, os serviços em geral com $57 \%$, com o acesso à informação com $58 \%$ e os estudos com $54,4 \%$, estão num segundo grupo. A acessibilidade aos edifícios com $42,5 \%$, as barreiras arquitetónicas com $46 \%$, as ofertas de tempos livres, desporto e cultura com $49,6 \%$, transportes com $45,3 \%$ e oportunidades laborais $42,6 \%$, estão num terceiro grupo. Num quarto nível estão as categorias relacionadas com o plano de acessibilidades com $23,3 \%$ e a habitação com 19,8\%. No quadro 1 poder-se-á fazer uma síntese das áreas fortes, das áreas fracas e muito fracas e das áreas emergentes nas 31 cidades estudadas.

Através da aplicação de critérios relacionados com os recursos e os serviços disponíveis na cidade e o acesso aos mesmos (por exemplo: transportes, acessibilidades, acesso à informação, recursos educativos e formativos tempos livres, cultura, desporto, saúde, emprego e habitação...) foi possível selecionar duas cidades consideradas com maior potencial inclusivo.

As duas cidades, unidades de estudo, são cidades médias com alguns problemas de exclusão, muito conscientes da necessidade de promover a inclusão dos grupos mais marginalizados, que para o caso desenvolvem políticas com uma matriz fortemente social que se reflete nos projetos, nas medidas e ações que são levadas a cabo e que estão em linha com as recomendações dos autores que estudam as cidades inclusivas. Apoiam-se muito nos recursos endógenos e que desenvolvem processos de liderança que mobilizam a comunidade e que têm conseguido transformar e mudar a realidade, não sem dificuldades, no sentido de criar melhores condições de vida para os cidadãos em geral e em particular para os que, têm necessidades especiais. O motor da mudança, é uma forte e clara opção política de curto, médio e longo prazo, um forte empenho dos atores políticos e de uma forte articulação com os quadros técnicos, na constante procura de novos meios e de melhores soluções. Outra componente que ajuda a fazer de uma cidade, uma cidade inclusiva, é a sua relação com redes internacionais e o desenvolvimento dos projetos socioeducativos que funcionem como estratégia de mobilização para a transformação das realidades. Contudo, uma das áreas que requer ainda maior empenho e trabalho, técnico e político, das várias partes implicadas, mesmo em ambas as cidades, seja a participação dos interessados nos processos de mudança e na captação de meios acrescidos para o processo de transformação das cidades, num tempo compatível com a expetativa das pessoas e da sociedade.

\section{DISCUSSÃO E CONCLUSÕES}

Quando se optou por desenvolver o estudo, selecionando as cidades portuguesas que faziam parte das cidades educadoras, partiu-se do princípio que, se as cidades privilegiavam a educação como uma estratégia para influenciar o desenvolvimento das suas comunidades nos seus mais diversos domínios, isso seria uma vantagem para o desenvolvimento dos processos de inclusão social.

A aceção de educação que está subjacente à investigação é a que se definiu a partir de Gomez, Freitas e Callejas (2007), numa perspetiva da vida comunitária que influencia os processos de socialização, de modo a que as pessoas vão aprendendo, ensinando, partilhando os conhecimentos que facilitam a 
compreensão, interpretação e a transformação da realidade. Neste sentido, todos os agentes da comunidade podem ser agentes educativos, na medida em que interagem mutuamente, num dado território e numa dada comunidade, em que a formação das pessoas e a sua influência sobre a sociedade são um esforço educativo para a promoção do desenvolvimento, da inclusão e da coesão social.

Foi essa a realidade que este estudo ajudou a constatar, recenseando os projetos desenvolvidos nas cidades com esse objetivo e observando, segundo a categorização de Trilla Brenet (1999), nítidas características que associam algumas das cidades à construção do que se pode definir por uma cidade educadora. Primeira característica, adaptabilidade e dinamismo, que se revela na capacidade que a cidade tem de se adaptar à mudança e às novas necessidades, procurando respostas educativas face às novas realidades sociais, culturais, pobreza, marginalidade, etc. Segunda característica, compensação, que se corporiza pelo aumento dos recursos educativos de uma cidade, funcionando como fator de discriminação positiva face a situações como os problemas económicos, as desigualdades, as necessidades especiais, ou seja, através do enriquecimento do meio procura-se compensar as dificuldades. Refere o autor que, deste modo, os territórios podem desempenhar uma função de equidade no caso das pessoas que, por algum motivo, estão em risco social ou de desenvolvimento. Terceira característica, o espaço público, como espaço privilegiado para as aprendizagens informais, para as trocas, para a sociabilidade, para a convivência. É no espaço público que muito do currículo implícito da cidade se desenvolve em múltiplas atividades que ajudam a transmitir conhecimento, valores, tradições e práticas sociais, que são importantes nos processos de pertença e de inclusão na comunidade. Ficou patente neste estudo que conforme refere Rodrigues (2003) «a inclusão é um conceito multifacetado que pode ser abordado a partir de variados pontos de partida e que não tem, necessariamente, pontos de chegada semelhantes. Assume, ainda, que a inclusão ao nível da educação não pode ser dissociada da inclusão social ao nível mais lato» (p.9).

\section{REFERÊNCIAS BIBLIOGRÁFICAS}

Associação Internacional das Cidades Educadoras. Carta das Cidades Educadoras. Disponível em: http://www.edcities.org/ wp-content/uploads/2013/10/Carta-Portugues.pdf.

Ball, S. (1994). Political Interviews and the Politics of Interviewing. Em G. Waldorf, Researching the Powerful in Eucation (pp. 96-115). Londres: UCL Press.

Caballo Vilar, M. (2001). A Cidade Educadora. Lisboa: Instituto Piaget.

Caride, J. (1994). A educación nos processos de desenvolvimento comunitário: cara un proxecto de integración escola-comunidade. Santiago de Compostela: Universidade de Santiago de Compostela.

Del Pozo, J. (2003). Les Politiques Municipals en Educació. Simposio Internacional: La Millora de Les Oportunitats Educativas en la Societitat en Transformació. Barcelona.

Del Pozo, J. (2013). O Conceito de «Cidade Educadora» Hoje. Em Educação e Vida Urbana: 20 Anos de Cidades Educadoras (pp. 22-30). Torres Novas: Rede Portuguesa das Cidades Educadoras.

Faure, E. (1972). La Educación del Futuro. Madrid: Alianza/Unesco.

Fernandes, A. S. (s.d.). Cidade Educativa Novas Perspectivas das Politicas Educativas. Disponível em: https://www.google. com/\#q=CIDADE+EDUCADORA\%3A+NOVAS+PERSPECTIVAS+DAS+POL\%C3\%8DTICAS+EDUCATIVAS.

Garcia Garrido, J. L. (1991). Fundamentos de Educación Comparada. Madrid: Dykinson.

Gomez, J., Freitas, O., e Callejas, G. (2007). Educação e Desenvolvimento Comunitário Local. Porto: Profediições.

Mathew, J.C. (31-01-2018) La Urbanización en el Siglo XXI Repensar la Ciudad [DVD].

Disponível em: https://www.facebook.com/ajuntamentdelleida/videos/3132549690094311/.

Phillips Jr., J. (1977). Teoria de Piaget Sobre as Origens do Intelecto. Lisboa: Socicultura.

Rodrigues, D. (2003). Perspectivas Sobre Inclusão - da educação à sociedade. Porto: Porto Editora.

Subirats, J. (2003). Participación y Resposabilidades de la Comunidade en la Educacion. Revista de Educatión, 330, $217-236$.

Trilla Brenet, J. (1999). La Cludad Educadora. Cuadernos de Pedagogia, nº 278, 44-50. 